\title{
Severity of alcohol dependence in patients with alcoholic liver disease
}

\author{
A D WODAK, J B SAUNDERS, I EWUSI-MENSAH，M DAVIS， ROGER WILLIAMS
}

\begin{abstract}
To determine the severity of dependence on alcohol in patients with alcoholic liver disease the severity of alcohol dependence questionnaire was administered to 193 patients with various types of alcoholic liver disease established histologically, in whom a detailed history of lifetime alcohol consumption was also obtained. Only 34 patients $(18 \%)$ were classified as being severely dependent compared with $56 \%$ of patients without overt liver disease who were attending a neighbouring alcohol treatment unit. There was a significant correlation between the severity of dependence and mean daily alcohol consumption ( $r=0.45$ and 0.39 for men and women, respectively) but not duration of drinking. Dependence scores tended to be lower in patients with cirrhosis than in those with precirrhotic liver disease, but this difference reached significance only in women.

These findings confirm that patients who develop chronic alcoholic liver disease are usually only mildly dependent on alcohol and support the hypothesis that patients who escape florid symptoms of alcohol dependence are at greater risk of developing liver damage because they are able to sustain a continual consumption of alcohol over many years.
\end{abstract}

\section{Introduction}

Chronic alcohol consumption can result in both tolerance to alcohol and dependence on it. ${ }^{1}$ In this respect alcohol is similar to many other psychoactive drugs. Dependence has interrelated physical and psychological components and implies an alteration in drinking behaviour that develops partly as a learnt response to certain cues, such as a particular drinking environment, and also to alleviate withdrawal symptoms. ${ }^{23}$ The physiological and prognostic importance of dependence was emphasised in the 1977 report of the World Health Organisation Scientific Group on Alcohol-Related Disabilities. ${ }^{4}$

The drinking behaviour of dependent subjects differs from that of non-dependent subjects in several ways. Dependent subjects consume larger quantities of alcoholic drinks within a given time and, when drinks of disguised alcohol content are used, of non-alcoholic drinks too. ${ }^{56}$ Severely dependent alcoholics drink faster and report a stronger desire to drink after a priming dose of alcohol than those with a lesser degree of dependence. ${ }^{7}$ When fully developed alcohol dependence tends to be self perpetuating, and its severity has important implications for treatment and prognosis. For example, highly dependent drinkers are less likely to succeed in a controlled drinking programme than those who are less dependent. ${ }^{8} 9$

\footnotetext{
Liver Unit, King's College Hospital and Medical School, London SE5 8RX

A D WODAK, FRACP, honorary senior registrar

J B SAUNDERS, MRCP, lecturer

I EWUSI-MENSAH, MRCPSYCH, honorary senior registrar

M DAVIS, MRCP, consultant physician
}

ROGER WILLIAMS, FRCP, consultant physician and director of liver unit

Correspondence and requests for reprints to: Dr J B Saunders.
Previous studies investigating alcohol dependence have been largely confined to patients seeking treatment in psychiatric units. Heavy drinkers are a heterogenous group, and patients who develop physical complications, such as liver disease, seem to differ in many respects from those presenting with social or psychological problems. Attention was drawn to these different forms in the mid-1940s by Jellinek, who defined " $\beta$ alcoholics" as those who were not dependent on alcohol but who often succumbed to medical complications, whereas " $\gamma$ alcoholics" were highly dependent and suffered severe behavioural problems and psychiatric complications. ${ }^{10}$ This view is not, however, universally held. Glatt, on the basis of his extensive clinical experience, concluded that patients with chronic physical damage are usually highly dependent, ${ }^{11}$ and Skinner and Allen, using a questionnaire technique, found that alcohol dependence correlated with physical sequelae of alcohol consumption. ${ }^{12}$

For some time we have been impressed by the rarity of severe symptoms of alcohol withdrawal in patients admitted for investigation of alcoholic liver disease. In view of the importance of dependence as a core feature of alcoholism ${ }^{4}$ and its prognostic importance we investigated the severity of alcohol dependence in a group of patients with alcoholic liver disease using a well validated, self administered questionnaire. ${ }^{13}$

\section{Patients and methods}

We studied 126 men (aged 23-68 (mean 48.9 (SE 1.0)) years) and 67 women (aged 23-71 (mean 49.1 (1.4)) years) who were admitted to the liver unit with alcoholic liver disease between 1979 and 1981 The criteria for inclusion in the study were that: (1) this was the patient's first admission to the liver unit; (2) there was a history of alcohol consumption of at least $40 \mathrm{~g}$ a day for five years or more; (3) liver biopsy showed alcohol related liver disease as judged by a specialist histopathologist; and (4) no cause for liver disease other than chronic alcohol consumption was found. From a consecutive group of 240 such patients 47 were excluded from the study: 21 were too ill to cooperate; eight had a history of hepatic encephalopathy; and 18 had evidence of intellectual impairment on clinical testing of cognitive function.

One hundred and eight of the patients $(56 \%)$ presented with jaundice, ascites, or variceal haemorrhage while the remaining patients were referred for investigation of abnormal liver function tests (37), non-specific symptoms (39), or alcohol intoxication (nine). Liver biopsy showed alcoholic cirrhosis, with or without alcoholic hepatitis, in $135(70 \%)$, alcoholic hepatitis without cirrhosis in $28(15 \%)$, and fatty liver with or without fibrosis in $30(16 \%)$.

Assessment of alcohol intake-Lifetime alcohol consumption was elicited by one of two clinicians (ADW or JBS), who used a standardised and validated interview schedule. ${ }^{14}$ From the detailed information obtained various measures of alcohol intake were calculated-namely, the duration of drinking more than $40 \mathrm{~g}$ alcohol/day; the mean daily alcohol intake during this time; the corresponding cumulative alcohol intake and lifetime alcohol intake; the daily intake at the time referred to in the severity of alcohol dependence questionnaire; the maximum daily alcohol intake over a period of at least one year; and the mean daily intake in the three months before presentation.

Assessment of dependence-After the interview patients were asked to complete a severity of alcohol dependence questionnaire, which was devised according to guidelines of a World Health Organisation committee 4 and has been validated by comparison with a clinician's rating of dependence ${ }^{13}$ and, more recently, by correlation with withdrawal symptoms after admission for treatment. ${ }^{15}$ This questionnaire contains 16 questions on physical withdrawal symptoms, affective withdrawal, relief of withdrawal symptoms by drinking, and reinstate- 
ment of dependence and refers to a recent period in which the patient was drinking heavily in a way that was typical of a heavy drinking period. Daily alcohol consumption during this time is assessed by four additional questions. Two scores were then computed: the "SADQ 60 " score, based on all 20 questions and having a maximum value of 60 , and the "SADQ 48," which was calculated after the questions on daily alcohol consumption had been excluded. The correlation of the latter score with alcohol intake as established by the interview schedule was calculated. For the full SADQ 60 a score of 15 to 30 was taken as indicating moderate dependence and a score of 31 or more as indicating severe dependence. ${ }^{15}$

Data storage and analysis-Data were stored in a CDC $6600 \mathrm{com}-$ puter and analysed by means of the program suite statistical package for the social sciences. ${ }^{16}$ Statistical significance was assessed by the $\chi^{2}$ test (with Yates's correction when necessary) and Student's $t$ test (two tail) as appropriate. Results are expressed as means (SE).

\section{Results}

Dependence scores-Most patients $(121 ; 63 \%)$ had either no or only mild dependence (table I); of these, 26 scored only on the questions on daily alcohol consumption. Only 34 patients ( 25 men $(19 \cdot 8 \%)$ and nine women (13.4\%)) had a score of more than 30 and would be classified as being severely dependent. Mean scores for the SADQ 60 were $15.6(1.2)$ for men and $10.8(1.5)$ for women $(p<0.02)$, the corresponding SADQ 48 scores being $10.9(1.0)$ and $8.1(1.3)$, respectively $(p>0 \cdot 10)$.

TABLE I-Severity of alcohol dependence* in patients with alcohol induced liver disease. (Figures are numbers $(\%)$ of patients)

\begin{tabular}{lccc}
\hline $\begin{array}{l}\text { Alcohol dependence } \\
\text { (score) }\end{array}$ & $\begin{array}{c}\text { Men } \\
(\mathrm{n}=126)\end{array}$ & $\begin{array}{c}\text { Women } \\
(\mathrm{n}=67)\end{array}$ & $\begin{array}{c}\text { Total } \\
(\mathrm{n}=193)\end{array}$ \\
\hline None or minimal $(<15)$ & $71(56)$ & $50(75)$ & $121(63)$ \\
Moderate $(15-30)$ & $30(24)$ & $8(12)$ & $38(20)$ \\
Severe $(>31)$ & $25(20)$ & $9(13)$ & $34(17)$ \\
\hline
\end{tabular}

*As determined by the "SADQ 60 " score.

Relation to alcohol intake-The patients' mean daily alcohol intake ranged from 42 to $329 \mathrm{~g} /$ day and their duration of drinking over 40 $\mathrm{g} /$ day from five to 51 years. At the time referred to in the questionnaire 29 patients $(15 \cdot 0 \%)$ were drinking less than $80 \mathrm{~g} /$ day, $92(47 \cdot 7 \%)$ between 80 and $160 \mathrm{~g}$, and $72(37.3 \%)$ more than $160 \mathrm{~g}$; the average intake was higher in men (201 (11) g) than in women $(117(9) \mathrm{g})(\mathrm{p}<$ $0.001)$. For 177 of the 193 patients $(91.7 \%$ ) this represented their maximum consumption ever, and in the remaining 16 the intake was typical of that in the five years before they presented with liver disease, although at some stage previously it had been higher $(180 \mathrm{~g} v 103 \mathrm{~g})$.

TABLE II-Relation of dependence score (" $S A D Q 48$ ") to various measures of alcohol intake

\begin{tabular}{|c|c|c|c|c|}
\hline & \multicolumn{2}{|c|}{ Men } & \multicolumn{2}{|c|}{ Women } \\
\hline & $\mathbf{r}$ & p & $\mathbf{r}$ & p \\
\hline \multirow{5}{*}{$\begin{array}{l}\text { Mean daily intake at time } \\
\text { indicated in questionnaire } \\
\text { Mean daily intake }(\mathrm{g}) \text { when } \\
\text { consumption }>40 \mathrm{~g} / \mathrm{day} \\
\text { Maximum daily intake }(\mathrm{g}) \\
\text { Recent daily intake }(\mathrm{g}) \\
\text { Duration of drinking } \\
>40 \mathrm{~g} / \text { day (years) } \\
\text { Cumulative intake }(\mathrm{kg}) \text { when } \\
\text { consumption }>40 \mathrm{~g} / \text { day } \\
\text { Cumulative lifetime alcohol } \\
\text { intake }(\mathrm{kg})\end{array}$} & 0.46 & $<0.0001$ & $0 \cdot 41$ & $<0.001$ \\
\hline & $\begin{array}{l}0 \cdot 45 \\
0 \cdot 40 \\
0 \cdot 40\end{array}$ & $\begin{array}{l}<0.0001 \\
<0.0001 \\
<0.0001\end{array}$ & $\begin{array}{l}0.39 \\
0.35 \\
0.29\end{array}$ & $\begin{array}{l}<0.001 \\
<0.002 \\
<0.01\end{array}$ \\
\hline & -0.12 & NS & $-0 \cdot 16$ & NS \\
\hline & $0 \cdot 17$ & $<0.02$ & 0.09 & NS \\
\hline & 0.19 & $<0.02$ & 0.07 & NS \\
\hline
\end{tabular}

The severity of dependence. score (SADQ 48) correlated most closely with daily alcohol intake. The strongest relations were with daily intake at the time indicated on the questionnaire, maximum daily intake, and mean intake over the whole period of heavy drinking (table II). There was no significant correlation between the severity of dependence and duration of drinking.

Relation to severity of liver disease-In both sexes there was a tendency for increasing severity of liver disease to be associated with lower dependence, though the difference reached significance only in women (table III). This may reflect differences in the mode of presentation between patients with precirrhotic disease and those with cirrhosis. Patients with precirrhotic disease more commonly presented with alcohol intoxication $(16 \%)$ than did patients with cirrhosis $(2 \%)$.

TABLE III-Relation of dependence scores (mean $(S E)$ ) to severity of liver disease

\begin{tabular}{lccc}
\hline & $\begin{array}{c}\text { Precirrhotic } \\
\text { disease }\end{array}$ & Cirrhosis & $\mathrm{p}$ \\
\hline & & "SADQ $60 "$ & \\
Men & $18.3(2 \cdot 4)$ & $14.4(1.4)$ & $\mathrm{NS}$ \\
Women & $18.1(3.3)$ & $7.9(1.5)$ & $<0.005$ \\
& & " $S A D Q 48 "$ & \\
Men & $13.0(2 \cdot 1)$ & $10 \cdot 1(1.2)$ & $\mathrm{NS}$ \\
Women & $14.2(3.0)$ & $5.7(1.3)$ & $<0.02$ \\
\hline
\end{tabular}

\section{Discussion}

The major finding in this study was that most patients with alcohol related liver disease had low scores for alcohol dependence. This is in contrast to the findings in a study carried out in a neighbouring alcohol treatment centre, where dependence scores were much higher (for men the mean SADQ 60 score was $33.8(1.9)$ and for women $33.2(3.3))$ and where $56 \%$ of patients were classified as severely dependent. ${ }^{15}$ The latter group had presented primarily with social or psychological problems due to their drinking. They were also younger than our patients (men 42.1 (1.3) years, women 39.7 (2.9) years; $\mathrm{p}<0.05$ for both comparisons) ( $\mathrm{T}$ Stockwell, personal communication).

The severity of dependence was found to correlate highly with average daily alcohol intake, and the higher dependence scores of patients attending the alcoholism treatment unit probably reflect their heavier daily alcohol intake. All of them habitually drank more than $100 \mathrm{~g}$ alcohol a day in heavy drinking periods, and their mean daily alcohol intake was 374 (25) $\mathrm{g}$ for men and 203 (28) $\mathrm{g}$ for women ( $\mathrm{T}$ Stockwell, personal communication). An alternative explanation is that some constitutional factor influences the degree of dependence that develops at a given level of alcohol consumption, but there is no evidence for this in man.

These results may help to explain the enigma that only $15 \%$ of heavy drinkers develop chronic liver disease. Subjects whose average intake is very high would tend to become severely dependent and either present at a fairly early stage for treatment or spontaneously modify their drinking habits, at least intermittently. Others who drink at levels that are insufficient to produce severe dependence but that, none the less, are hepatotoxic would not see the need to modify their drinking habits; some would continue to drink heavily over many years and ultimately develop cirrhosis. It is possible that as liver disease develops patients' tolerance for alcohol is reduced, but this is unlikely to be the explanation for the low dependence scores in our patients as for $92 \%$ the questionnaire referred to the period when their drinking was at its heaviest.

The fact that most patients with chronic alcoholic liver disease have only a mild degree of dependence should not be taken to indicate that controlled drinking would be a satisfactory option after discharge from hospital. For such a group abstinence from alcohol is mandatory as this significantly improves life expectancy. 1718 It does suggest, however, that this group of patients would respond to an educational approach combined with simple supportive treatment as opposed to the more intensive treatment that is required for more dependent patients to achieve abstinence.

This work forms part of a multidisciplinary programme of research into alcoholic liver disease, and we gratefully acknowledge the support of the Department of Health and Social Security and the Brewers' 
Society, London. We are grateful to Dr B Portmann for interpreting the liver biopsies. We thank Dr T Stockwell and Dr R Hodgson, of the Addiction Research Unit, for their help and advice and for providing the data on patients admitted to an alcohol treatment unit. We are grateful to Professor Griffith Edwards for constructive criticism of this manuscript.

\section{References}

${ }^{1}$ Edwards G. The treatment of drinking problems. London: Grant McIntyre, 1982.

${ }^{2}$ Edwards G, Gross MM. Alcohol dependence: provisional description of a clinical syndrome. $\mathrm{Br}$ Med f 1976; i:1058-61.

${ }^{3}$ Hodgson R, Stockwell T, Rankin H, Edwards G. Alcohol dependence: the concept, its utility and measurement. $B r \mathcal{F}$ Addict $1978 ; 73: 339-42$.

${ }^{4}$ Edwards G, Gross MM, Keller M, Moser J, Room R, eds. Alcohol-related disabilities. Geneva: WHO Offset publications, 1977. (No 32.)

${ }^{5}$ Schaeffer HH, Sobell MB, Mills KC. Base line drinking behaviours in alcoholics and social drinkers. Kinds of drink and sip magnitude. Behav Res Ther $1971 ; 9: 23-7$.

6 Marlatt GA, Denning B, Reid JB. Loss of control drinking in alcoholics: an experimental analogue. $\mathcal{F}$ Abnorm Psychol 1973;81:233-41.

7 Hodgson R, Rankin H, Stockwell T. Alcohol dependence and the priming effect. Behav Res Ther 1979;17:379-87.
${ }^{8}$ Orford J, Oppenheim E, Edwards G. Abstinence or control: the outcome for excessive drinkers two years after consultation. Behav Res Ther 1976;14:409-18.

${ }^{9}$ Armor DJ. The Rand reports and the analysis of relapse. In: Edwards G, Grant M, eds. Alcoholism treatment in transition. London: Croom Helm, 1980:81-94.

${ }^{10}$ Jellinek EM. The disease concept of alcoholism. New Haven: Hillhouse Press, 1960:36-41.

11 Glatt M. Alcoholism. Sevenoaks: Hodder and Stoughton, 1982.

2 Skinner HA, Allen BA. Alcohol dependence syndrome: measurement andê validation. F Abnorm Psychol 1982;91:199-209.

13 Stockwell T, Hodgson R, Edwards G, Taylor C, Rankin H. The develop-ç ment of a questionnaire to measure severity of alcohol dependenceBr ₹ Addict 1979;74:79-87.

14 Saunders JB, Wodak AD, Haines A, et al. Accelerated development of alcoholic cirrhosis in patients with HLA-B8. Lancet 1982;1:1381-4.

15 Stockwell T, Murphy D, Hodgson R. The severity of alcohol dependence questionnaire: its use, reliability and validity. $B r \mathcal{F}$ Addirt 1983;78:은 $145-55$.

${ }_{16} \mathrm{Nie} \mathrm{N}$, Hull $\mathrm{CH}$, Jenkins JG, Steinbrenner $\mathrm{K}$, Bent DH. Statistical package for the social sciences. New York: McGraw Hill, 1975.

17 Powell LJ, Klatskin G. Duration of survival in Laennec's cirrhosis. Am 7 Med 1968;42:406-20.

18 Saunders JB, Walters JRF, Davies P, Paton A. A 20-year prospective study of cirrhosis. Br Med F 1981 ;282:263-6.

(Accepted 8 August 1983)

\title{
Prospective study of post-transfusion hepatitis after cardiac surgery in a British centre
}

\author{
J D COLLINS, M F BASSENDINE, A A CODD, A COLLINS, R E FERNER, O F W JAMES
}

\begin{abstract}
A series of 248 consecutive patients undergoing cardiac surgery were examined in a prospective study of posttransfusion hepatitis in a single British centre. Patients received a total of 1796 units of blood or blood products (mean blood transfusion 6.28 units per patient). During five to 30 days after operation 38 of the patients showed an increase in serum transaminase activities. There was no serological evidence for fresh infection by hepatitis $A$ or B virus, cytomegalovirus, Epstein-Barr virus, or herpes virus in any of these patients. The increase in transaminase activities was unexplained and reached over $100 \mathrm{IU} / 1$ (normal $<40 \mathrm{IU} / 1)$ in six patients. The incidence of acute short incubation post-transfusion non-A, non-B hepatitis was therefore thought to be $2.4 \%$.
\end{abstract}

Department of Medicine, Freeman Hospital, Newcastle upon Tyne, NE7 7DN

J D COLLINS, MB, MRCP, research fellow

M F BASSENDINE, BSC, MRCP, first assistant in medicine

R E FERNER, MSC, MRCP, registrar

O F W JAMES, BM, FRCP, reader in medicine (geriatrics)

Department of Virology, Newcastle General Hospital, Newcastle upon Tyne NE4 6BE

A A CODD, MD, DIP BACT, consultant virologist

Northern Regional Blood Transfusion Service, Newcastle upon Tyne

A COLLINS, MB, BS, MRCPATH, consultant haematologist

Correspondence to: Dr O F W James.
These six patients had normal liver function six months after transfusion but a further two of the surviving 228 patients had raised serum transaminase activities at six매 months. In one of these, liver biopsy disclosed chronic persistent hepatitis; in the other, alcoholic liver disease was suspected. The incidence of significant chronic liver disease after blood transfusion possibly attributable to a non-A, non-B hepatitis agent was therefore only $0.4 \%$

\section{Introduction}

No major British prospective study of post-transfusion hepatitis has been carried out in the era of sensitive serological tests to@ exclude infection with hepatitis A virus or hepatitis $B$ virus, thus no clear indication of the recent incidence of post-trans-은 fusion non-A, non-B hepatitis in Britain is available. In tho most recent major British study conducted between 1969 and? $1971,{ }^{1}$ in which tests for hepatitis B surface antigen (HBsAg) and anti-HBs were carried out by immunodiffusion, the probable incidence of non-A, non-B post-transfusion hepatitis was 30 out of 768 patients $(3.9 \%)$.

We decided to study non-A, non-B post-transfusion hepatitis in a single centre in Britain; in particular we wished to examine the frequency with which clinically significant chronic liver disease might arise.

\section{Patients and methods}

We studied prospectively 248 consecutive patients over the age of 16 who were undergoing both routine and emergency cardiac surgery A clinical history and results of examination were recorded for each patient, taking particular note of previous jaundice, hepatitis, blood transfusion, drug treatment, and the presence of liver disease. 